\title{
John Law \& Evelyn Ruppert (eds) (forthcoming, 2016) Modes of Knowing: Resources from the Baroque. Manchester: Mattering Press. ISBN 978-0-9931449-8-1.
}

\author{
Benjamin Alberti \\ balberti@framingham.edu
}

\section{A Fifth Mode of Knowing}

The challenge for Modes of Knowing: Resources from the Baroque is this: how can "cultivating a baroque sensibility" (Verran \& Winthereik) reveal and hold onto the messy and otherworldly experiences we encounter in research without, simultaneously, smothering them with an excess of words? The goal of a particularly baroque mode of knowing (the fifth of five such modes that John Law quickly sketches at the opening of his introductory chapter) is to go beyond the boundaries of the academic in answering the question, "How should we know the world?" How do we "get at the richness of experience that escapes social science representation" (Verran \& Winthereik)? Most chapters in the volume (all by established figures) struggle faithfully with what this might mean for their research projects. Mobilizing heterogeneous materials and inspired by baroque and contemporary art, music, architecture, food, stones, Indigenous concepts and numbers the authors work to release social science research from its own constraints. To this end, the volume is a success, though, inevitably, questions linger.

Coherence among chapters is strong, with many references to Law's introduction (in which he lays out the characteristics of a baroque mode of knowing through reflections on Bernini's sculptures). The volume is firmly positioned at the leading edge of the methodological concerns of STS (though certainly not limited to this field), and is characteristic of Law's (e.g., 2004) work. I am enthusiastic about this project, which follows the creed that reality is enacted and knowing, therefore, is embedded in practices. As Evelyn Ruppert puts it: "Methods do not stand apart as representations of social worlds; they also perform those social worlds."

Even so, the nature of the task suggests a contrivance. Is "baroque" simply a faddish way to describe what we are already doing? As van de Port reminds us, Hellen Hills (2011:31) in Rethinking the Baroque warns that the concept is readily extendable and risks becoming meaningless. However staged the effort, the charge to "think baroque" has produced some wonderful effects, principally for two reasons. First, the deliberate staging turns out to be important; and second, the materials that are engaged with, whether "of the Baroque" or "baroquely," reveal a material excess that pushes and prods the authors to explore "different kinds of realities" (Law).

Mining the baroque for concepts, Law provides a list of baroque techniques of knowing. I did shuffle a little in my seat at the happy coincidence that several of these terms, and others used frequently, seemed delightfully close to those of our most cherished contemporary theorists, such as the ease with which Deleuzian concepts resonate with Law's Baroque. MacKenzie's chapter on statistical probability and big data, for example, where he convincingly makes the case for postdemographic probability in which individuals themselves are distributive numbers, or "modes of 
the world," was unsurprisingly close to a Deleuzian reading of Leibniz' monad. Similarly, the concept of "performativity" featured frequently. Hennion's chapter used it to explain the nineteenth-century reinvention of J.S. Bach's music (and public), which led to fierce debates about authenticity. Baroque music exists only in the reiterated playing. Physicist Karen Barad appears on the fringes of several papers; her mechanistic world-formulae seeming strangely at odds with a baroque orientation (though Blaser's summary of Barad's diffractive method is exceptionally good).

Curiously, Raffles' chapter makes no mention of baroque. Either, generously, Raffles simply distills a baroque sensibility or, less generously, one could identify his work as Baroque if one wanted to. That is, one needn't. What is it, then, that a Baroque mode of knowing has to offer that other approaches don't? The concept of "excess" appears frequently in the volume, and I think is a good part of its success. It is used as a mark of the ineffable, the element of experience beyond the reach of conventional research. Van de Port, for example, is concerned with the perennial ethnographic question of how to reconcile the excesses of fieldwork with the narrative style of traditional anthropological accounts. Baroque is open to representational modes that get at the "rest of what is" (excess). Blaser shows most clearly how excess can be generative, diffracting it through the Yshiro concept of the yrmo as an "illuminating shadow" to analyze the incommensurability of understandings of what is going on during community workshops on conservation.

The excess that I find most compelling lies in the incredible array of things, materials, colors, sounds, forms (folds), artworks, and sensualities; it is materials first almost always. Verran and Winthereik's particularly lucid chapter presents a contrast between the technoscience engineering object (exemplified by a diagram presenting the potential steps towards promoting wave energy innovation) and a sixteenth century baldachin (a tapestry throne canopy). Both are diagrams, devices that are "ephemeral clots of material semiotic resources" with the dual function of representation and "pilotage" (material guides towards future action). The technoscience diagram represents but does not guide; its aim is non-contradiction. The baldachin does both materially foregrounding "complexity, openness, and emergence" and enabling equivocation. Hugh Raffles' in search of the London Stone is guided by multiple traces of its material life. The Stone in fact "tangles" time. Its slow, oolitic life of geological time and hard materiality would appear to anchor it - but it is repeatedly cut adrift by Raffles' fractured description until it more closely resembles a fluid vortex. And what would appear to be a contrast, therefore, with the clafoutis - the sugary fruit dessert of Mol's wonderfully evocative chapter - turns out to be none at all. Mol argues that unlike a baroque church (or the London stone, say) in which the parts are permanently held together, the baroque coherence of the clafoutis (a composite figure composed of the absence/presence of diverse worlds) is just as resilient.

Prodded by the material excess of artworks, neat interpretations are visually unsettled. Descriptions of Bernini's sculptures are used to great effect by Law to draw out the conceptual apparatus of a baroque mode of knowing. Ruppert, in turn, uses the $(\mathrm{x})$ trees project by artist Agnes Chavez - in which subjects can introduce text via data visualization technologies - to suggest how enactive research can incorporate the experiences of it by its subjects. But this material excess also reveals a problem. In his study of lapinhas, montages of Our Child Jesus on the Mountain, and baroque churches in Bahia, van de Port argues we should experience a baroque aesthetics rather than grasp its meaning. The challenge is how to get this into our academic texts, as he points out. Such attempts always enact cuts: Bernini stands in for Baroque in general; the description and images of the Igreja de São Francisco in Bahia limit what is essentially an overwhelming experience, a "golden storm."

A baroque coherence is undoubtedly achieved by the book, though questions remain (as they should - baroque points towards "apertures" not closures). For example, what would happen if such foundational STS concepts as performativity were themselves subjected to the full force of the baroque material? And uneasiness or a self-consciousness can be detected among some authors about the book's staging. But Baroque 
performances were lavish theatrical productions, very deliberately contrived, and ones that you could not easily escape, "to see it all you are forced to step inside the theatre," as Law reminds us. And this is surely part of exactly this project.

\section{References}

Hills H (ed) (2011) Rethinking the Baroque. Farnham: Ashgate Publishing Limited.

Law J (2004) After Method. London \& New York: Routledge. 